\title{
Recruitment determines differences between assemblages on shaded or unshaded seawalls
}

\author{
D. J. Blockley* , M. G. Chapman \\ Centre for Research on Ecological Impacts of Coastal Cities, Marine Ecology Laboratories, A11, University of Sydney, \\ New South Wales 2006, Australia
}

\begin{abstract}
The distribution of intertidal organisms can often be determined by processes operating at the time of recruitment. Recruitment has been demonstrated to influence the composition of assemblages of natural habitats, but there is less evidence of its importance in artificial habitats. Coastal areas are becoming increasingly urbanised, with the replacement of many natural habitats by man-made structures. It is, therefore, important to test processes that influence the structure of assemblages in artificial habitats in order to evaluate whether processes act in a way that is predictable from knowledge of natural shores. Much of the foreshore of Sydney Harbour has been replaced by seawalls, many of which are built in association with wharves. It has been shown that features of wharves may cause small-scale differences between assemblages on adjacent sections of seawalls which are under or not under wharves. The present study tested the hypothesis that these patterns are determined by differences in recruitment, by monitoring recruitment to experimental clearings and settlement plates in both habitats. In general, algae and mobile invertebrates had greater cover or abundance on unshaded seawalls, while sessile invertebrates had greater cover on shaded seawalls. Not all taxa in these habitats recruited to experimental clearings or plates, but the abundance or cover of those that did resembled patterns observed in the surrounding established assemblage. This indicates that, at least for some organisms on intertidal seawalls, patterns of distribution are determined at the time of recruitment and are probably influenced by shading. Furthermore, patterns in the present study were similar to what was predicted from work done on natural shores, showing that studies from natural shores can be applied to these artificial habitats.
\end{abstract}

KEY WORDS: Seawalls $\cdot$ Wharves $\cdot$ Recruitment $\cdot$ Urbanised estuary $\cdot$ Algae $\cdot$ Sessile filter-feeders Grazers

Resale or republication not permitted without written consent of the publisher

\section{INTRODUCTION}

Patterns of distribution of organisms can often be determined by recruitment into specific habitats (Underwood \& Fairweather 1989, Roughgarden et al. 1994), although post-recruitment processes, such as competition (Dayton 1975), predation (Menge 1976), or physical stress (Garrity 1984), can modify initial patterns. Recruitment has been shown to vary spatially and temporally, especially for intertidal plants and animals (Denley \& Underwood 1979, Connell 1985). Variability in recruitment at large spatial scales can result from variations in larval supply (e.g. currents delivering larvae to some locations and not to others; Minchinton \& Scheibling 1991), while at smaller scales, active behavioural processes and features of the substratum become important in determining the distribution of organisms (Mullineaux \& Butman 1991).

Active larval choice and preferential settlement onto the substratum are important in determining distribution and abundance of organisms, with physical factors such as surface texture and chemistry, shear stress and patterns of water flow influencing patterns of settlement of invertebrates and algae (Mullineaux \& Butman 1991, Goldberg \& Foster 2002). Although differential mortality at the time of settlement or shortly thereafter 
may also affect patterns of distribution and abundance (Keough \& Downes 1982, Connell 1985), this is often difficult to distinguish from variable initial settlement. Patterns of recruitment, therefore, reflect patterns of settlement and mortality occurring within a short time of settlement (Keough \& Downes 1982, Connell 1985). Much of the variation in assemblages among different seawalls may be due to larval responses to features of the substratum, such as surface complexity and range of microhabitats (Archambault \& Bourget 1996) or the material from which it is composed (McGuinness 1989).

Assemblages of intertidal algae and invertebrates differ among seawalls in Sydney Harbour, Australia, at the scale of metres to kilometres (Chapman \& Bulleri 2003, Bulleri et al. 2005). Even though seawalls are structurally simpler than natural shores, this range of variation is similar to that of natural rocky shores in New South Wales (Bulleri et al. 2005). Despite variability at multiple scales, assemblages on seawalls have been found to show consistent differences at scales of 10 s of metres in response to larger features of the habitat (Blockley in press, Bulleri et al. 2005). The presence of structures such as wharves or jetties, which overhang sections of the seawall, can have a large effect on intertidal assemblages, with the cover of algae and abundance of mobile invertebrates greater on sections of seawalls not under wharves, while sessile invertebrates can have greater cover under wharves (Blockley in press).

Seawalls are often continuous structures, consisting of the same material and with similar surface complexity over the scale of 10 s to 100 s of metres. Any differences in recruitment at this scale, therefore, are unlikely to be in response to surface features. These patterns might be explained by organisms responding to shading by wharves at the time of recruitment. Larvae of sessile invertebrates have been shown to respond to light, with many recruiting in greater numbers to shaded surfaces (Maughan 2001). Algae, in contrast, have been shown to recruit in greater numbers to unshaded than shaded patches of shore (Clark et al. 2004). A similar pattern has been demonstrated for subtidal artificial structures. Glasby (1999) showed that, for subtidal pilings, recruitment of foliose algae was greater to unshaded clearing, while sessile invertebrates had greater recruitment to shaded clearings. It is possible that this will be similar for intertidal artificial structures, such as seawalls.

In the present study we tested the hypothesis that the patterns of difference found between assemblages on seawalls under or not under wharves at certain locations within Sydney Harbour (Blockley in press) are, first, found at other locations in Sydney Harbour and, second, that these patterns are established at the time of recruitment.

\section{MATERIALS AND METHODS}

Patterns of difference between taxa on seawalls under or not under a wharf. To first test the hypothesis that assemblages would differ between seawalls under (hereafter shaded) or not under a wharf (hereafter unshaded), 2 sites were sampled under the main wharf and 2 outside the wharf at Rose Bay in Sydney Harbour (Fig. 1). The 2 unshaded sites outside the wharf were located on either side of a smaller wharf (see Fig. 1). It was not possible to avoid potentially confounding effects by having unshaded sites on either side of the main wharf because a boat ramp and rubble embankment made one side of the wharf unusable. Each site was approximately $5 \mathrm{~m}$ wide and $10 \mathrm{~m}$ from adjacent
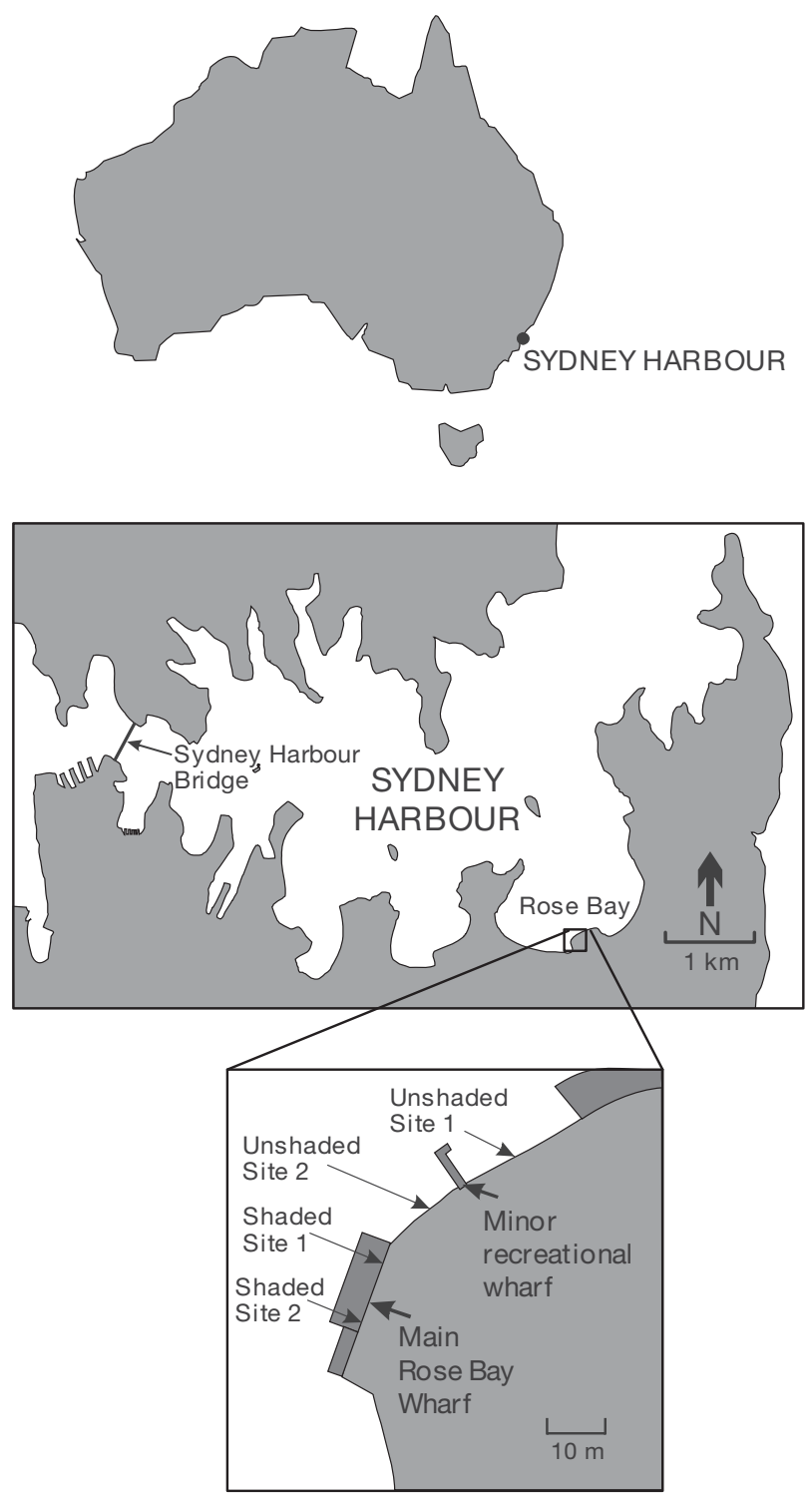

Fig. 1. Study site in Sydney Harbour, Australia 
sites. Three tidal heights were sampled in each site. These were 1.2 to $1.4,0.9$ to 1.1 and 0.6 to $0.8 \mathrm{~m}$ above Chart Datum, henceforth referred to as high-, mid- and low-tidal heights, respectively.

Sites were sampled in January 2002, with 6 replicate $20 \times 25 \mathrm{~cm}$ quadrats haphazardly placed at each site. Quadrats were placed at least $1 \mathrm{~m}$ from the edge of the wharf to avoid any possible edge effects (People 2006). Covers of sessile animals and algae were estimated from 50 regularly spaced points, and all mobile animals were counted in each quadrat. All organisms were identified to species, except where this was impossible without destructive sampling (e.g. sponges and some small filamentous algae).

Recruitment onto plates and clearings. Adult or established organisms can affect recruitment of intertidal organisms onto the substratum (e.g. Dayton 1971, Denley \& Underwood 1979). The established assemblages differed between seawalls under or not under wharves. Patches of substratum were, therefore, cleared in each of these habitats to eliminate any effect of existing assemblages in a test for effects of the presence/absence of the wharf on recruitment. Recruitment was measured in these clearings, which were thus of the same age, size and without existing biota in each habitat.

Despite attempts to standardise these patches, there is a potential for confounding results because the existing assemblage may influence small-scale damage due to clearing (e.g. greater cover of oysters under wharves meant that the seawall in this habitat had to be cleared with greater force). If so, differences between clearing methods in the 2 habitats may mean that cleared patches are not the same in both habitats. Therefore, to test for potential differences in the substratum in the clearings, sandstone plates were also attached to sections of seawalls under or not under the wharves. These plates provided a standardised substratum, of the same material as the seawall, in each habitat, against which results from clearings could be compared.

Plates were attached to seawalls and patches of seawall were cleared in each of these habitats in June 2001. At each site, 24 patches were cleared at the midtidal height using paint scrapers, steel chisels and wire brushes. Twenty-four $15 \times 15 \mathrm{~cm}$ sandstone plates, composed of the same material as the seawall, but with smooth surfaces, were attached to the wall at the same time as clearings were made. Plates and clearings were interspersed haphazardly and were separated from adjacent plates or clearings by 10 s of centimetres.

Plates and cleared patches of seawall were sampled 1, 3, 5 and 8 mo after clearings were made and plates first attached to the walls. The timing of sampling was largely determined by access to the site, which was restricted by construction and maintenance work around the area of the wharf. At each time, 6 different plates and cleared patches, randomly assigned to each sampling time, were sampled so that data were temporally independent. Plates and clearings were sampled using a $13 \times 13 \mathrm{~cm}$ quadrat, with the outer $1 \mathrm{~cm}$ edge of the plates or clearings not sampled to avoid any possible edge effects (Bulleri et al. 2005). This also helped to distinguish between recruitment and overgrowth from sessile species around the edges. There was also a $2.5 \mathrm{~cm}$ diameter circle in the middle of the quadrat that was not sampled to avoid any effect of the bolt that attached plates to the substratum.

The percentage covers of sessile invertebrates and algae were estimated from regularly spaced points, while mobile invertebrates were counted within the whole quadrat. We only counted small mobile invertebrates, less than approximately $5 \mathrm{~mm}$ wide, with individuals larger than this ignored. These small individuals were chosen because they were more likely to have recruited after the onset of the experiment (Bulleri et al. 2005).

Statistical analysis. For all analyses, heights were treated separately, as there were no hypotheses being tested concerning differences among heights and each height represented a different assemblage (Chapman \& Bulleri 2003). The hypothesis of differences between assemblages on shaded and unshaded seawalls was therefore tested separately for 3 intertidal assemblages.

Comparisons of abundance or cover for individual taxa from established assemblages and from recruits were analysed using analysis of variance (ANOVA). Most variances were found to be heterogeneous from a Cochran's test of homogeneity of variances (Underwood 1999). Attempts to stabilise variances through transformation of the data were largely unsuccessful, and so untransformed data were used for all analyses, as ANOVAs are relatively robust to heterogeneous variances if there are many estimates of variance (Underwood 1999). Nevertheless, because of the increased likelihood of Type I error, a more conservative significance level was used when testing for differences (i.e. where Cochran's test had $\mathrm{p}<0.05 \mathrm{p}_{\text {crit }}$ was 0.01 , where Cochran's test had $p<0.01 p_{\text {crit }}$ was 0.001 ), except where Cochran's test was not significant.

\section{RESULTS}

\section{Differences in established assemblages between habitats}

At the high-tidal height, most of the available area on the unshaded seawall was either bare or occupied by the red encrusting alga Hildenbrandia rubra and 
the oysters Saccostrea glomerata. A similar pattern was found at the midtidal height, except that there was little or no bare space. At the low-tidal height, the tubeworm Galeolaria caespitosa as well as the algae Corallina officinalis and a mix of Enteromorpha intestinalis and Ulva lactuca were the major occupiers of space on the unshaded seawall.

There was little algal cover on the shaded seawall at any height, most of the space being occupied by a mix of sessile invertebrates. At all heights, the oyster Saccostrea glomerata was a major occupier of space, with a complex of encrusting orange sponges also having a large cover low on the shore. Other species found on the shaded seawall, albeit with a relatively small cover, were the tubeworm Galeolaria caespitosa, the introduced oyster Crassostrea gigas, the barnacle Tetraclitella purpurascens (highshore) and the mussel Mytilus galloprovincialis (mid- and low-shore).

There was a general pattern, although not statistically significant, of greater cover of algae on unshaded seawalls and greater cover of sessile invertebrates on shaded seawalls (Table 1). These patterns are illustrated for all algae and Saccostrea glomerata, Tetraclitella purpurascens and the orange sponge (Fig. 2, Table 1).

The patterns were less clear at the high-tidal height because of large between-site variability. Despite this, for at least one of the sites and generally across sites, cover was much greater on the shaded seawall for most sessile invertebrates (e.g. Saccostrea glomerata), while the cover of the alga Hildenbrandia rubra was greater on the unshaded wall (Fig. 2, Table 1). The mid- and lowtidal heights showed a much clearer pattern of difference between shaded and unshaded walls for cover of sessile invertebrates (e.g. Tetraclitella purpurascens at the mid-tidal height and orange sponge at the low-tidal heights were greater on shaded walls) and algae (e.g. H. rubra, Corallina officinalis and foliose green algae at the low-tidal height were greater on unshaded walls) (Fig. 2). The same pattern of greater cover on seawalls under wharves was observed for other common sessile invertebrates at mid- and low-shore (e.g. Saccostrea
Table 1. Analyses of individual taxa for sections of seawall under or not under wharves. Cochran's test for homogeneity of variance was significant $(p<0.01)$ for most analyses, so between-habitat differences were interpreted as significant at $\mathrm{p}<0.001$, except: ${ }^{1}$ Cochran's test not significant and so habitats significantly different at $\mathrm{p}<0.05 ;{ }^{2}$ Cochran's test $\mathrm{p}<0.05$ and so habitats significantly different at $\mathrm{p}<0.01\left(\mathrm{MS}_{\mathrm{H}}\right.$ : mean square for habitat; $\mathrm{MS}_{\mathrm{S}}$ : site $(\mathrm{H}) ; \mathrm{MS}_{\mathrm{Res}}$ : residual $\mathrm{MS}_{\mathrm{p}}$ : pooled sites with residual). Degrees of freedom $=1$ and 2 , except where pooled $\left({ }^{p}\right)(\mathrm{df}=1$ and 22 ). Results in bold indicate significant difference between habitats. Patterns of qualitative difference between means shown in last column (S: shaded seawall; U: unshaded seawall)

\begin{tabular}{|c|c|c|c|c|c|c|}
\hline & $\mathrm{MS}_{\mathrm{H}}$ & $\mathrm{MS}_{\mathrm{S}}$ & $\mathrm{MS}_{\mathrm{Res}}$ & $\mathrm{MS}_{\mathrm{P}}$ & $F$ & $\begin{array}{l}\text { Qualitative } \\
\text { difference }\end{array}$ \\
\hline \multicolumn{7}{|l|}{ High-tidal height } \\
\hline Hildenbrandia rubra & 661.5 & 542.8 & 218.2 & & 1.2 & $\mathrm{~S}<\mathrm{U}$ \\
\hline${ }^{1}$ Saccostrea glomerata & 1768.2 & 5941.5 & 302.0 & & 0.3 & $\mathrm{~S}>\mathrm{U}$ \\
\hline Crassostrea gigas & 287.0 & 176.0 & 34.5 & & 1.6 & $\mathrm{~S}>\mathrm{U}$ \\
\hline Galeolaria caespitosa & 3197.0 & 3390.4 & 120.7 & & 0.9 & $\mathrm{~S}>\mathrm{U}$ \\
\hline${ }^{2}$ Tetraclitella purpurascens & 253.5 & 254.2 & 10.5 & & 1.0 & $\mathrm{~S}>\mathrm{U}$ \\
\hline Elminius covertus & 0.3 & 0.3 & 0.0 & & 1.0 & $\mathrm{~S}>\mathrm{U}$ \\
\hline Chthamalus antennatus & 5.0 & 2.0 & 0.3 & & 2.5 & $\mathrm{~S}<\mathrm{U}$ \\
\hline${ }^{2}$ Chiton pelliserpentis ${ }^{\mathrm{p}}$ & 16.7 & 3.0 & 2.4 & 2.4 & 6.9 & $\mathbf{S}<\mathbf{U}$ \\
\hline Siphonaria denticulata ${ }^{\mathbf{p}}$ & 9.4 & 0.0 & 2.8 & 2.5 & 3.7 & $\mathrm{~S}<\mathrm{U}$ \\
\hline \multicolumn{7}{|l|}{ Mid-tidal height } \\
\hline H. rubra & 3382.0 & 692.3 & 140.6 & & 4.9 & $\mathrm{~S}<\mathrm{U}$ \\
\hline Corallina officinalis & 2.0 & 0.4 & 0.2 & & 5.4 & $\mathrm{~S}<\mathrm{U}$ \\
\hline${ }^{1} S$. glomerata & 2504.0 & 887.6 & 402.3 & & 2.8 & $\mathrm{~S}>\mathrm{U}$ \\
\hline Mytilus galloprovincialis & 204.2 & 187.1 & 122.5 & & 1.1 & $\mathrm{~S}>\mathrm{U}$ \\
\hline G. caespitosa & 35.3 & 18.8 & 9.5 & & 1.9 & $\mathrm{~S}<\mathrm{U}$ \\
\hline Austrobalanus imperator & 2.7 & 2.7 & 0.6 & & 1.0 & $\mathrm{~S}>\mathrm{U}$ \\
\hline${ }^{1}$ Ibla quadrivalvis ${ }^{\mathrm{p}}$ & 1.0 & 0.2 & 0.2 & 0.2 & 5.0 & $\mathbf{S}<\mathbf{U}$ \\
\hline${ }^{2}$ Tesseropora rosea & 5.0 & 0.4 & 0.1 & & 13.4 & $\mathrm{~S}<\mathrm{U}$ \\
\hline T. purpurascens $\mathbf{p}$ & 2.7 & 0.4 & 0.9 & 0.9 & 3.1 & $\mathrm{~S}>\mathrm{U}$ \\
\hline Orange sponge ${ }^{p}$ & 1457.0 & 198.4 & 143.1 & 148.1 & 9.8 & $\mathrm{~S}>\mathrm{U}$ \\
\hline${ }^{1}$ C. pelliserpentis ${ }^{p}$ & 140.2 & 0.7 & 2.4 & 2.3 & 62.1 & $\mathbf{S}<\mathbf{U}$ \\
\hline${ }^{1} S$. denticulata ${ }^{\mathrm{p}}$ & 0.7 & 0.0 & 0.1 & 0.1 & 5.5 & $\mathbf{S}<\mathbf{U}$ \\
\hline${ }^{1}$ Montfortula rugosa & 112.7 & 30.4 & 2.2 & & 3.7 & $\mathrm{~S}<\mathrm{U}$ \\
\hline${ }^{2}$ Cellana tramoserica ${ }^{p}$ & 5.0 & 0.0 & 0.5 & 0.5 & 10.2 & $\mathbf{S}<\mathbf{U}$ \\
\hline \multicolumn{7}{|l|}{ Low-tidal height } \\
\hline C. officinalis & 950.0 & 532.7 & 55.2 & & 1.8 & $\mathrm{~S}<\mathrm{U}$ \\
\hline Foliose green algae & 1751.0 & 1162.0 & 254.6 & & 1.5 & $\mathrm{~S}<\mathrm{U}$ \\
\hline${ }^{2} S$. glomerata & 5017.0 & 1029.0 & 456.4 & & 4.9 & $\mathrm{~S}>\mathrm{U}$ \\
\hline M. galloprovincialis & 198.4 & 108.4 & 9.0 & & 1.8 & $\mathrm{~S}>\mathrm{U}$ \\
\hline G. caespitosa & 17388.2 & 3408.8 & 327.6 & & 5.1 & $\mathrm{~S}<\mathrm{U}$ \\
\hline Hydroides spp. & 57.0 & 22.0 & 6.9 & & 2.6 & $\mathrm{~S}>\mathrm{U}$ \\
\hline A. imperator & 16.7 & 19.4 & 3.1 & & 0.9 & $\mathrm{~S}>\mathrm{U}$ \\
\hline T. rosea & 4.2 & 0.7 & 0.3 & & 6.3 & $\mathrm{~S}<\mathrm{U}$ \\
\hline T. purpurascens ${ }^{\mathbf{p}}$ & 2.0 & 2.0 & 1.4 & 1.5 & 1.4 & $\mathrm{~S}>\mathrm{U}$ \\
\hline Orange sponge & 9204.2 & 1410.8 & 339.9 & & 6.5 & $\mathrm{~S}>\mathrm{U}$ \\
\hline Watersipora spp. ${ }^{\mathbf{p}}$ & 71.8 & 13.6 & 14.8 & 14.7 & 4.9 & $\mathrm{~S}>\mathrm{U}$ \\
\hline
\end{tabular}

glomerata, Mytilus galloprovincialis and the barnacle Austrobalanus imperator) and by the tubeworm Hydroides spp. and the encrusting bryozoan Watersipora spp. low on the shore (Table 1).

Some sessile invertebrates showed exceptions to the general pattern and had greater cover on the unshaded seawall, e.g. the barnacles Chthamalus antennatus (high-shore) and Ibla quadrivalvis (mid-shore), 


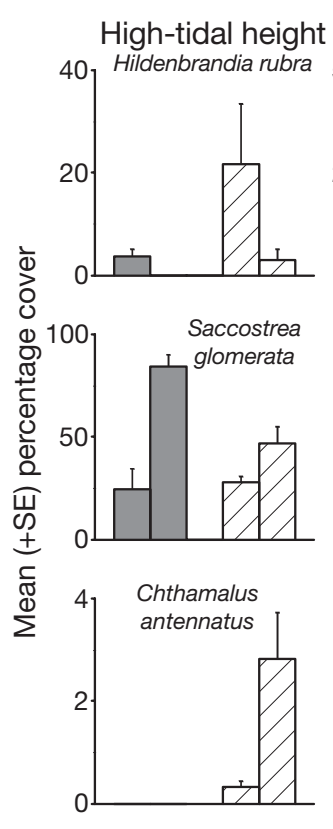

Mid-tidal height Low-tidal height
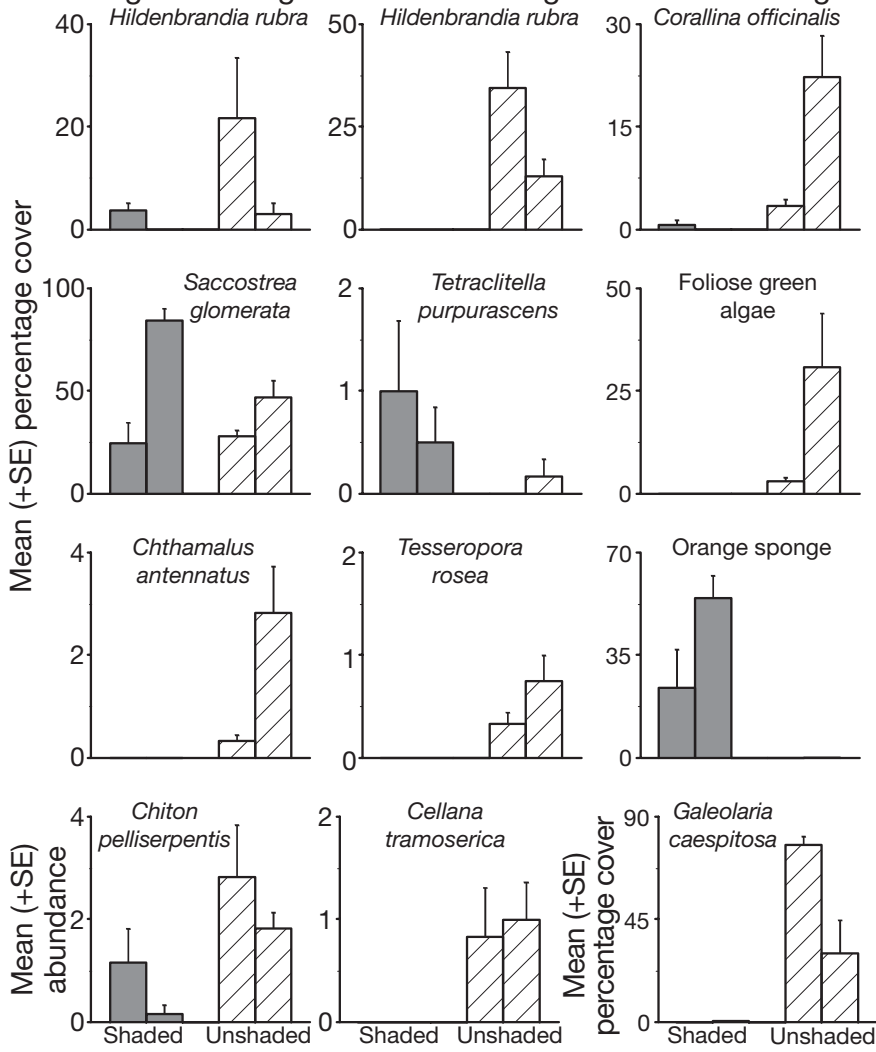

Fig. 2. Mean percentage cover or abundance of organisms in established assemblages at different tidal heights on shaded seawalls (grey) or unshaded seawalls (diagonal lines)

Tesseropora rosea (mid- and low-shore) and Galeolaria caespitosa (mid- and low-shore) (Fig. 2). All of these had a relatively small cover, with the exception of G. caespitosa, which dominated low-shore space on the unshaded seawall.

Mobile invertebrates, largely limpets and chitons, were more abundant on unshaded seawalls (Table 1), shown for Chiton pelliserpentis at the high-tidal height and Cellana tramoserica at the mid-tidal height (Fig. 2), although similar patterns were shown by the limpets Siphonaria denticulata and Montfortula rugosa. In contrast to the algae and sessile animals, differences in mean densities between habitats were significant for most mobile invertebrates (Table 1).

\section{Recruitment into clearings}

Patterns of recruitment differed among the 3 main types of algae. In contrast to what was predicted, the encrusting alga Hildenbrandia rubra did not show significant differences between habitats (Table 2), recruiting similarly to clearings in both habitats
(Fig. 3). The predicted pattern of greater recruitment to unshaded clearings was found for Corallina officinalis and foliose green algae (Fig. 3), although this was not statistically significant (Table 2). Cover of $C$. officinalis increased over time, whereas foliose green algae showed a large initial recruitment, but decreased in cover over time (Fig. 3).

Most sessile invertebrates did not recruit much until 5 mo after the start of the experiment, possibly due to seasonality in delivery of propagules. The encrusting orange sponges and the barnacles Tetraclitella purpurascens and Austrobalanus imperator recruited more to clearings on sections of shaded seawall (Fig. 3), as predicted. This pattern was, however, only statistically significant for $T$. purpurascens and only after 8 mo. Given the pattern observed in the adult population, the tubiculous polychaete Galeolaria caespitosa and the barnacle Tesseropora rosea were predicted to recruit more to unshaded clearings. There was, however, no significant, nor apparent, difference between habitats for G. caespitosa (Fig. 3, Table 2). Greater recruitment on unshaded seawalls was observed for $T$. rosea, although there was a great deal of variability in this species' recruitment (Fig. 3).

Abundances of limpets and of Chiton pelliserpentis were generally greater on the unshaded seawalls (Fig. 3), reflecting the pattern of the adult populations. The observed between-habitat differences in recruitment were, however, not statistically significant (Table 2), possibly because of the lack of statistical power. Furthermore, the observed differences decreased to almost 0 after 8 mo (Fig. 3).

\section{Comparisons between plates and clearing}

Recruitment to plates, like that to clearings, was initially low. Greater abundance or covers were recorded by the last 2 sampling times. For this reason, only the last sampling time was used when testing for differences in recruitment between clearings and plates.

For some taxa (e.g. the algae Hildenbrandia rubra and Corallina officinalis, the tube worm Galeolaria caespitosa, orange sponges and Chiton pelliserpentis), there was much less recruitment onto plates than onto clearings (Fig. 4). The barnacle Tesseropora rosea, however, showed significantly greater cover on plates at 1 site for each of the habitats (Table 3). Most of the remaining taxa showed similar patterns between the 2 substrata (Fig. 4, Table 3). This indicates that the features of the substratum are not causing differences in recruitment between habitats, plates being standard units in both habitats, but that some feature of the wharves is causing the differences. 
Table 2. Analyses of individual taxa of: (a) algae, (b) sessile invertebrates and (c) mobile invertebrates recruiting to clearings on sections of seawall under or not under wharves. Cochran's test for homogeneity of variance was significant $(\mathrm{p}<0.01)$ and so a more conservative significance level of $\mathrm{p}<0.001\left(^{*}\right)$ was used (NT: no test could be done; ${ }^{\mathrm{p}}$ : pooled factors). Where analyses showed significant interactions, F-ratios are not given for main effects and lower order interactions because these cannot be logically interpreted (full taxonomic designations, see Table 1)

\begin{tabular}{|c|c|c|c|c|c|c|c|}
\hline Source & df & MS & $F$ & MS & $F$ & MS & $F$ \\
\hline (a) & & \multicolumn{2}{|c|}{ H. rubra } & \multicolumn{2}{|c|}{ C. officinalis } & \multicolumn{2}{|c|}{$\begin{array}{c}\text { Foliose green } \\
\text { algae }\end{array}$} \\
\hline Time $=\mathrm{T}$ & 3 & 2499.3 & 4.2 & 29.9 & 1.0 & 3151.4 & 2.9 \\
\hline Habitat = H & 1 & 0.1 & NT & 141.4 & NT & 36603.3 & NT \\
\hline Site(H) & 2 & 1847.5 & 3.1 & 82.2 & 2.8 & 11162.1 & 10.4 \\
\hline $\mathrm{T} \times \mathrm{H}$ & 3 & 88.8 & 0.2 & 29.9 & 1.0 & 3746.2 & 3.5 \\
\hline $\mathrm{T} \times \operatorname{Site}(\mathrm{H})$ & 6 & 602.5 & 1.6 & 29.2 & 3.2 & 1074.5 & 2.6 \\
\hline Residual & 80 & 388.3 & & 9.1 & & 377.6 & \\
\hline (b) & & \multicolumn{2}{|c|}{ Orange sponge } & \multicolumn{2}{|c|}{ T. purpurascens } & \multicolumn{2}{|c|}{ A. imperator } \\
\hline $\mathrm{T}$ & 3 & 13.9 & 0.4 & 34.5 & & 0.4 & 2.0 \\
\hline $\mathrm{H}$ & 1 & 146.3 & NT & 41.8 & & 0.5 & 1.5 \\
\hline Site $(\mathrm{H})$ & 2 & 31.7 & 0.9 & 8.4 & & 0.4 & 1.9 \\
\hline $\mathrm{T} \times \mathrm{H}$ & 3 & 13.4 & 0.4 & 24.9 & $7.1^{*}$ & $0.2^{p}$ & \\
\hline $\mathrm{T} \times \operatorname{Site}(\mathrm{H})$ & 6 & 37.3 & 2.5 & $4.4^{\mathrm{p}}$ & & $0.2^{\mathrm{p}}$ & \\
\hline Residual & 80 & 14.9 & & $3.4^{\mathrm{p}}$ & & $0.2^{\mathrm{p}}$ & \\
\hline \multirow[t]{2}{*}{ Pooled ${ }^{\mathrm{p}}$} & $86 / 89$ & & & 3.5 & & 0.2 & \\
\hline & & \multicolumn{2}{|c|}{ G. caespitosa } & \multicolumn{2}{|c|}{ T. rosea } & & \\
\hline $\mathrm{T}$ & 3 & 46.8 & $11.1^{*}$ & 0.6 & 1.7 & & \\
\hline $\mathrm{H}$ & 1 & 0.0 & 0.0 & 0.7 & 1.7 & & \\
\hline $\operatorname{Site}(H)^{p}$ & 2 & 4.8 & & 0 & & & \\
\hline $\mathrm{T} \times \mathrm{H}^{\mathrm{p}}$ & 3 & 0.1 & & 0.4 & & & \\
\hline $\mathrm{T} \times \operatorname{Site}(\mathrm{H})^{\mathrm{p}}$ & 6 & 2.3 & & 0.5 & & & \\
\hline Residual $^{\mathrm{p}}$ & 80 & 4.5 & & 0.4 & & & \\
\hline Pooled $^{\mathrm{p}}$ & 91 & 4.2 & & 0.4 & & & \\
\hline (c) & & \multicolumn{2}{|c|}{ Limpets } & \multicolumn{2}{|c|}{ C. pelliserpentis } & & \\
\hline $\mathrm{T}$ & 3 & 53.6 & 1.5 & 0.6 & 1.3 & & \\
\hline $\mathrm{H}$ & 1 & 412.5 & NT & 8.2 & 5.3 & & \\
\hline Site $(\mathrm{H})$ & 2 & 223.8 & 6.4 & 1.5 & 3.4 & & \\
\hline $\mathrm{T} \times \mathrm{H}$ & 3 & 50.8 & 1.5 & $0.4^{\mathrm{p}}$ & & & \\
\hline $\mathrm{T} \times \operatorname{Site}(\mathrm{H})$ & 6 & 34.9 & 2.2 & $0.3^{p}$ & & & \\
\hline Residual & 80 & 16.2 & & $0.5^{\mathrm{p}}$ & & & \\
\hline Pooled $^{\mathrm{p}}$ & 89 & & & 0.5 & & & \\
\hline
\end{tabular}

\section{DISCUSSION}

For adult populations, most sessile invertebrates had greater cover on shaded seawalls, with some exceptions. Algae had a greater cover and mobile invertebrates a greater abundance on unshaded seawalls. Recruitment was shown to be similar to that predicted from the adult distribution for some species, but for others there was no similarity between the pattern of recruitment and the distribution of adults. Recruitment may possibly explain the pattern of difference between shaded and unshaded seawalls for some, but not all, organisms, and so other processes are likely to influence distribution. Many of these patterns, although fairly clear, were not statistically significant. The spatial scale was also limited to 1 location, and so caution must be used when making broad generalisations until experiments are repeated at a larger scale.

The lack of statistical significance is an issue for the analyses. The unavoidably limited spatial replication means that the test for habitats only had 1 and 2 degrees of freedom, except when it was possible to pool sites. This is a problem of low statistical power due to limited replication (Underwood 1999). The more conservative critical values because of heterogeneity of variances also made it difficult to detect statistically significant differences. The mean square values for habitats are, however, large for many of these tests (Table 1). The obvious differences between means from the 2 habitats (Fig. 2) also lend support to the differences between habitats. This is an issue of statistically significant versus 'biologically significant' differences (Thomas 1997, Quinn \& Keough 2003), and patterns should not be dismissed out of hand because of the lack of power to detect significant effects.

The composition of assemblages living on intertidal seawalls varies at the scale of kilometres within Sydney Harbour, Australia (Bulleri et al. 2005). However, spatially consistent patterns of difference exist between shaded and unshaded seawalls across multiple locations (Blockley in press). Distributions of intertidal organisms can be strongly influenced by the shade, and incident light has been found to be less strong under wharves than in unshaded marine habitats (Burdick \& Short 1999, Blockley in press). This might account for the observed differences between habitats.

In the present study, algal cover was greater on unshaded seawalls, while algae were almost absent from walls shaded by wharves. Algae are generally less abundant in shaded habitats (Dayton 1975, Goldberg \& Foster 2002, Clark et al. 2004). Glasby (1999) similarly found less algal cover on wooden pilings compared to natural reefs, which was shown experimentally to be due to shading by marinas associated with the pilings. Shading by wharves or jetties has also been found to reduce the cover of seagrasses in urbanised estuaries (Burdick \& Short 1999), supporting 

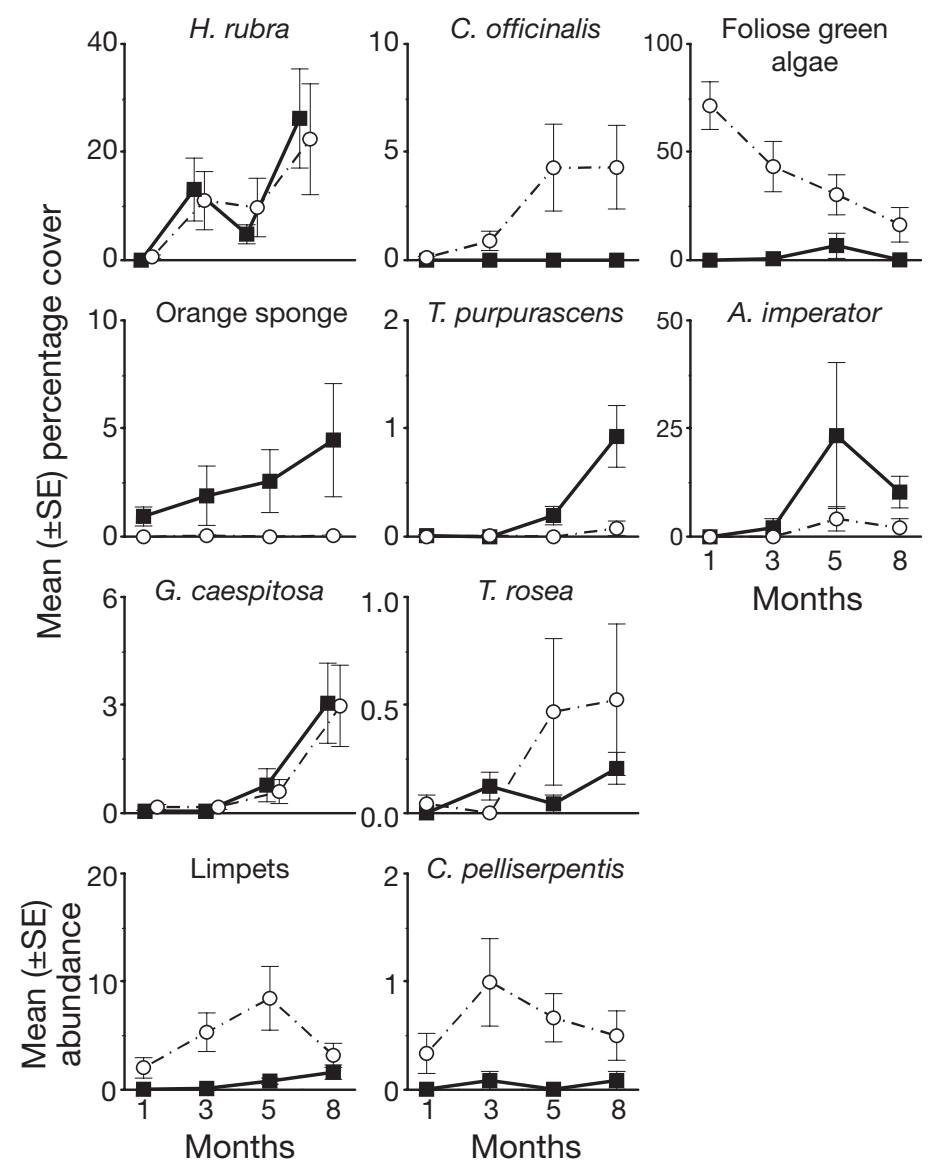

Fig. 3. Mean percentage cover or abundance of organisms recruiting to clearings at the mid-tidal height on shaded seawalls

(घ) or unshaded seawalls (o) 1, 3, 5 and 8 mo from beginning of experiment (full taxonomic designations, see Table 1)
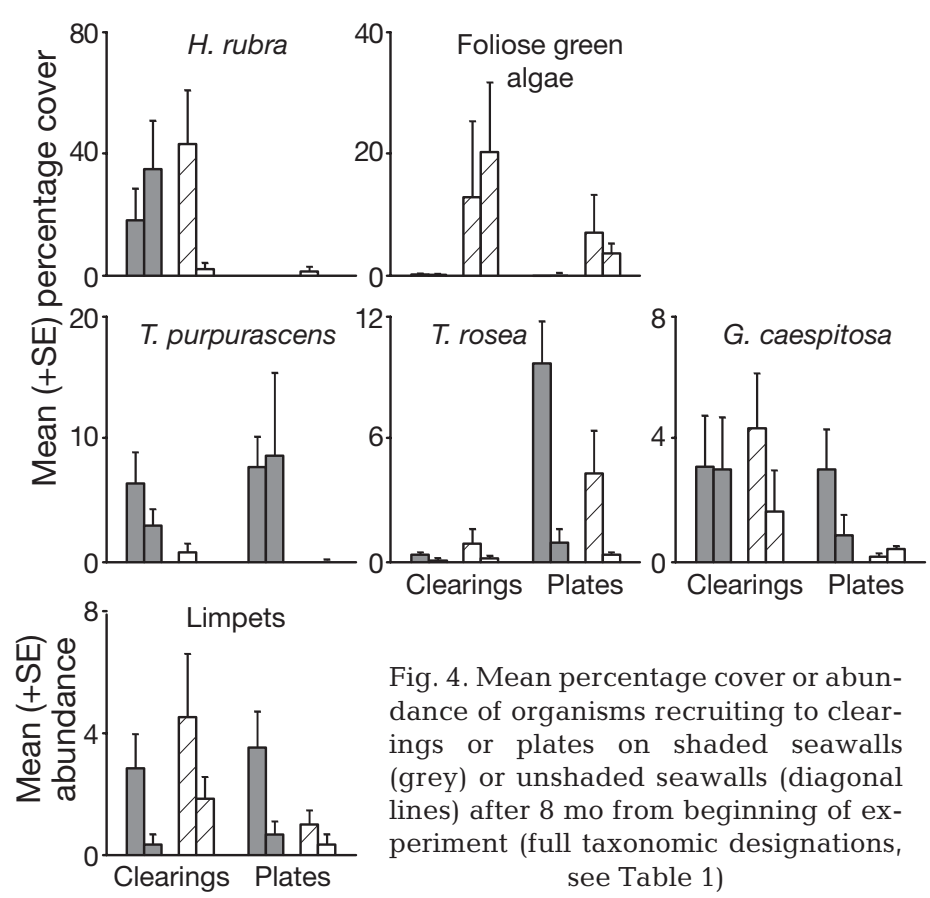

Fig. 4. Mean percentage cover or abundance of organisms recruiting to clearings or plates on shaded seawalls (grey) or unshaded seawalls (diagonal lines) after 8 mo from beginning of experiment (full taxonomic designations, see Table 1) the general pattern for the seawall at Rose Bay in the present study.

In the present study many common sessile invertebrates had greater cover on shaded seawalls. The distribution of sessile invertebrates can be affected by shade, with thermal stress greater on unshaded areas of rocky shore (Bertness et al. 1999). Shading can reduce surface temperatures and so reduce thermal stress (Williams 1994, Bertness et al. 1999). The patterns shown here for some of the sessile invertebrates may therefore be due to greater thermal stress on unshaded walls. There were, however, several exceptions, with the barnacles Chthamalus antennatus, Ibla quadrivalvis and Tesseropora rosea and the tubeworm Galeolaria caespitosa, all showing greater cover on unshaded seawalls. Variable patterns in T. rosea and G. caespitosa have been shown for other seawalls (Blockley in press), whereas $C$. antennatus had not been previously sampled. I. quadrivalvis is a cryptic species, which was found living in small cracks and crevices or amongst clumps of other animals, such as G. caespitosa, which may potentially reduce environmental stress (e.g. Bertness et al. 1999).

Mobile invertebrates were generally more abundant on unshaded seawalls in this study and throughout the harbour (Blockley in press). Grazing invertebrates are able to remain on the open shore, where algal cover is greater, and show behavioural responses to unfavourable conditions, such as high temperatures, by moving into spatial refuges (Garrity 1984). On seawalls, they may be using crevices between blocks of sandstone as spatial refugees to escape from extreme high temperatures, which allows them to persist on the unshaded wall where food availability is greatest. Alternatively, they may migrate into shaded patches only when temperatures are very hot and move back onto the unshaded wall when conditions are more benign. Whether the observed difference between shaded and unshaded portions of seawalls may be explained by behavioural responses to habitat differences cannot be tested here because there are few data on patterns of movement of mobile animals on intertidal seawalls (Bulleri et al. 2004).

Spatial variability of intertidal assemblages has been shown to be strongly influenced by patterns of recruitment for algae (Dayton 1971, Kaehler \& Williams 1997) and sessile and mobile invertebrates (Denley \& Underwood 1979, Connell 1985). Our experiments were done to test the hypothesis that patterns of recruitment may explain differences in abundances or covers of different taxa between shaded and unshaded portions of seawalls. Patterns of recruitment reflected those of established population for some, but not all, taxa. As predicted from the pattern of the established assemblage, Corallina officinalis and foliose green algae 
Table 3. Analyses of individual taxa of: (a) algae, (b) sessile invertebrates and (c) mobile invertebrates recruiting to clearings or plates on sections of seawall under or not under wharves. Cochran's test for homogeneity of variance was significant $(\mathrm{p}<0.01)$ for most analyses so habitats were interpreted as significantly different at $\mathrm{p}<0.001\left({ }^{*}\right)$, except: ${ }^{1}$ Cochran's test not significant and so habitats significantly different at $\mathrm{p}<0.05{ }^{2}$ Cochran's test $\mathrm{p}<0.05$ and so habitats significantly different at $\mathrm{p}<0.01$ ( ${ }^{\mathrm{p}}$ : pooled factors). Where analyses showed significant interactions, $F$-ratios are not given for main effects and lower order interactions because these cannot be logically interpreted (full taxonomic designations, see Table 1). C/P: Clearing/Plate

\begin{tabular}{|c|c|c|c|c|c|c|c|}
\hline Source & $\mathrm{df}$ & MS & $F$ & MS & $F$ & MS & $F$ \\
\hline (a) & & \multicolumn{2}{|c|}{ H. rubra } & \multicolumn{2}{|c|}{$\begin{array}{c}\text { Foliose green } \\
\text { alga }\end{array}$} & & \\
\hline $\mathrm{C} / \mathrm{P}$ & 1 & 7033.2 & 5.1 & 375.2 & 1.7 & & \\
\hline Habitat $=\mathrm{H}$ & 1 & 29.5 & 0.0 & 1399.6 & 6.3 & & \\
\hline Site $(\mathrm{H})$ & 2 & 1560.1 & 3.2 & $12.4^{\mathrm{p}}$ & & & \\
\hline $\mathrm{C} / \mathrm{P} \times \mathrm{H}$ & 1 & 63.7 & 0.1 & 369.6 & 1.7 & & \\
\hline $\mathrm{C} / \mathrm{P} \times \operatorname{Site}(\mathrm{H})$ & 2 & 1379.3 & 2.8 & $88.2^{\mathrm{p}}$ & & & \\
\hline Residual & 40 & 494.0 & & $241.0^{p}$ & & & \\
\hline Pooled ${ }^{p}$ & 44 & & & 223.6 & & & \\
\hline (b) & & \multicolumn{2}{|c|}{${ }^{2} T$. purpurascens } & \multicolumn{2}{|c|}{ T. rosea } & \multicolumn{2}{|c|}{${ }^{1}$ G. caespitosa } \\
\hline $\mathrm{C} / \mathrm{P}$ & 1 & 30.1 & $0.7 \mathrm{NS}$ & 144.0 & & 44.1 & $4.7^{*}$ \\
\hline $\mathrm{H}$ & 1 & 464.6 & $11.2^{*}$ & 21.5 & & 8.9 & 0.9 \\
\hline Site $(H)$ & 2 & $5.2^{\mathrm{p}}$ & & 77.9 & & $8.4^{\mathrm{p}}$ & \\
\hline $\mathrm{C} / \mathrm{P} \times \mathrm{H}$ & 1 & 44.7 & $1.1 \mathrm{NS}$ & 33.1 & & 7.5 & 0.8 \\
\hline $\mathrm{C} / \mathrm{P} \times \operatorname{Site}(\mathrm{H})$ & 2 & $15.2^{\mathrm{p}}$ & & 62.6 & $8.7^{*}$ & $9.9^{p}$ & \\
\hline Residual & 40 & $44.8^{p}$ & & 7.2 & & $9.5^{\mathrm{p}}$ & \\
\hline Pooled ${ }^{p}$ & 44 & 41.6 & & & & 9.5 & \\
\hline (c) & \multicolumn{3}{|c|}{ Limpets } & & & & \\
\hline $\mathrm{C} / \mathrm{P}$ & 1 & 12.0 & 2.1 & & & & \\
\hline $\mathrm{H}$ & 1 & 0.1 & 0.0 & & & & \\
\hline Site $(\mathrm{H})$ & 2 & 29.7 & 5.1 & & & & \\
\hline $\mathrm{C} / \mathrm{P} \times \mathrm{H}$ & 1 & 27.0 & 4.6 & & & & \\
\hline $\mathrm{C} / \mathrm{P} \times \operatorname{Site}(\mathrm{H})$ & 2 & $3.1^{\mathrm{p}}$ & & & & & \\
\hline Residual & 42 & $6.0^{\mathrm{p}}$ & & & & & \\
\hline Pooled ${ }^{\mathrm{p}}$ & 40 & 5.8 & & & & & \\
\hline
\end{tabular}

showed greater recruitment onto the unshaded seawall. Although lower temperature, as well as reduced desiccation, in shaded habitats may increase the growth of algae (Underwood \& Jernakoff 1984), low irradiance may reduce recruitment of algae, because spores that settle on shaded surfaces may fail to grow, resulting in greater post-settlement mortality (Goldberg \& Foster 2002). Thus, unshaded seawalls may have more algae because of greater recruitment, despite the potentially stressful conditions, with light levels under wharves reduced to a point where algae are unable to persist, even if they settle (Dayton 1975, Burdick \& Short 1999, Clark et al. 2004).

The barnacle Tesseropora rosea, which was predicted to have greater recruitment on unshaded seawalls, showed little difference in recruitment between habitats. Information on recruitment of sessile invertebrates was sparse, because so few recruited to either the clearings or plates. The complex of orange sponge and the barnacles Austrobalanus imperator and Tetra- clitella purpurascens recruited more to shaded clearings, with fewer recruiting to unshaded seawalls, consistent with what was predicted from the pattern of the adult population. Larvae of invertebrates can spend considerable time exploring the substratum before showing preferential settlement onto certain habitats (Keough \& Downes 1982). Sponges have been shown to recruit preferentially into their adult habitat (Maldonado \& Uriz 1998), as have species of barnacles (Connell 1985, Minchinton \& Scheibling 1991). It has previously been shown that recruitment of $T$. purpurascens was greater in areas that were shaded, while larvae of $T$. rosea settled equally on sunny and shaded shores, but survived better in the unshaded areas (Denley \& Underwood 1979). For barnacles, the data support the model that the effect of wharves is to alter patterns of recruitment on intertidal seawalls, in ways predictable from previous studies in natural habitats.

Some species of limpets showed no apparent difference in recruitment between habitats, although abundances of individual taxa were too small to analyse. In general and as predicted, most mobile invertebrates recruited in greater numbers to the unshaded seawall. This would support the hypothesis that spatial differences in abundance of some species were determined by differential recruitment. We cannot, however, dismiss the possibility that observed patterns were produced by post-recruitment displacement.

Other taxa, e.g. the encrusting alga Hildenbrandia rubra and tubeworm Galeolaria caespitosa, did not show any difference between recruitment into either habitat, despite differences between habitats in the adult populations. It seems, for these taxa, recruitment cannot explain the observed patterns of difference between shaded and unshaded seawalls in the adult population. Previous observations (Blockley in press) indicate that the cover of $G$. caespitosa is very variable among sites, although they generally had greater cover on unshaded seawalls. Individuals in the present study were recent recruits, and mortality of individuals might not occur until they are larger. Fairweather (1985) found that Morula marginalba, the only predator of G. caespitosa that was observed on seawalls in this experiment, shows size selectivity in its choice of prey, choosing adults over juvenile prey. If this was the 
case here, there may have been no difference in mortality until the worms reached a larger size. The abundance of predators would also have to be greater on seawalls under wharves, which is consistent with their behaviour of sheltering in shaded crevices and hollows (Fairweather 1988).

Hildenbrandia rubra generally had greater cover on seawalls not under wharves, but recruited to both habitats equally. Therefore, this pattern is probably not determined by recruitment. This contrasts with the study by Kaehler \& Williams (1997) for encrusting algae on tropical shores; these authors found that, although post-recruitment processes (e.g. grazing) had a small effect, distribution of crusts was largely determined by variability in recruitment. Underwood (2006) found that $H$. rubra can persist when heavily shaded if it remains physically connected to thalli that are not shaded. It might, therefore, be able to recruit to shaded habitats, but is eventually overgrown by more competitive sessile species (Underwood 2006). The timecourse of this experiment was such that overgrowth had not yet occurred, so the long-term persistence of $H$. rubra under wharves could not be measured.

The pattern of recruitment onto plates, as onto clearings, for most taxa was similar, indicating that clearings give a fairly accurate measure of the effect of wharves on recruitment without confounding trends by other factors that may be associated with the finescale topographic surfaces of the clearings. It is, therefore, likely that some feature associated with the wharves, rather than potential differences between patches of seawalls, is responsible for the differences in recruitment between the 2 habitats.

For many taxa, patterns of recruitment onto shaded seawalls were similar to those that would be predicted from studies in natural habitats. This suggests that these taxa are showing natural processes of recruitment in this artificial habitat. However, it does not necessarily follow that artificial and natural habitats are analogous. The area shaded by wharves is much greater than any similar area on rocky shores, such as overhangs and crevices. Even though organisms may be responding to shading by wharves in a similar way to shading on natural shores, the effect of such a large shaded area and such a different substrata (vertical wall versus near horizontal natural shore) could result in very different assemblages or interactions among intertidal organisms. Therefore, not only comparisons of patterns of distribution and abundance in artificial habitats must be studied, but also the processes that structure these patterns. If the processes do not affect organisms in a similar way to that on natural shores, then this could have long-term implications for the persistence of populations as urbanisation of the marine environment increases.
Acknowledgements. This study was supported by the Australian Research Council through the Centre for Research on Ecological Impacts of Coastal Cities and a University Postgraduate Award (D.J.B.). We are grateful to M. Bishop, V. Cole, K. Mitchie, S. Monteiro and J. People for help in the field and J. Moreira and 3 anonymous referees for useful comments on this manuscript.

\section{LITERATURE CITED}

Archambault P, Bourget E (1996) Scales of coastal heterogeneity and benthic intertidal species richness, diversity and abundance. Mar Ecol Prog Ser 136:111-121

Bertness MD, Leonard GH, Levine JM, Bruno JF (1999) Climate-driven interactions among rocky intertidal organisms caught between a rock and a hot place. Oecologia 120:446-450

Blockley DJ (in press) Effect of wharves on intertidal assemblages on seawalls in Sydney Harbour, Australia. Mar Environ Res

Bulleri F, Chapman MG, Underwood AJ (2004) Patterns of movement of the limpet Cellana tramoserica on rocky shores and retaining seawalls. Mar Ecol Prog Ser 281: 121-129

Bulleri F, Chapman MG, Underwood AJ (2005) Intertidal assemblages on seawalls and vertical rocky shores in Sydney Harbour (Australia). Aust Ecol 30:655-667

Burdick DM, Short FT (1999) The effects of boat docks on eelgrass beds in coastal waters of Massachusetts. Environ Manage 23:231-249

Chapman MG, Bulleri F (2003) Intertidal seawalls: new features of landscape in intertidal environments. Landsc Urban Plann 62:159-172

Clark RP, Edwards MS, Foster MS (2004) Effects of shade from multiple kelp canopies on an understory algal assemblage. Mar Ecol Prog Ser 267:107-119

Connell JH (1985) The consequences of variation in initial settlement versus post-settlement mortality in rocky intertidal communities. J Exp Mar Biol Ecol 93:11-46

Dayton PK (1971) Competition, disturbance and community organization: the provision and subsequent utilization of space in a rocky intertidal community. Ecol Monogr 41: 351-389

Dayton PK (1975) Experimental evaluation of ecological dominance in a rocky intertidal algal community. Ecol Monogr 45:137-159

Denley EJ, Underwood AJ (1979) Experiments on factors influencing settlement, survival, and growth of two species of barnacles in New South Wales. J Exp Mar Biol Ecol 36: 269-293

Fairweather PG (1985) Differential predation on alternative prey, and the survival of rocky intertidal organisms in New South Wales. J Exp Mar Biol Ecol 89:135-165

Fairweather PG (1988) Predation creates haloes of bare space among prey on rocky seashores in New South Wales. Aust J Ecol 13:401-409

Garrity SD (1984) Some adaptations of gastropods to physical stress on a tropical rocky shore. Ecology 65: 559-574

Glasby TM (1999) Effects of shading on subtidal epibiotic assemblages. J Exp Mar Biol Ecol 234:275-290

Goldberg NA, Foster MS (2002) Settlement and postsettlement processes limit the abundance of the geniculate coralline alga Calliarthron on subtidal walls. J Exp Mar Biol Ecol 278:31-45

Kaehler S, Williams GA (1997) Do factors influencing recruit- 
ment ultimately determine the distribution and abundance of encrusting algae on seasonal tropical shores? Mar Ecol Prog Ser 156:87-96

Keough MJ, Downes BJ (1982) Recruitment of marine invertebrates: the role of active choices and early mortality. Oecologia 54:348-352

Maldonado M, Uriz MJ (1998) Microrefuge exploitation by subtidal encrusting sponges: patterns of settlement and post-settlement survival. Mar Ecol Prog Ser 174:141-150

Maughan BC (2001) The effects of sedimentation and light on recruitment and development of a temperate, subtidal, epifaunal community. J Exp Mar Biol Ecol 256:59-71

McGuinness KA (1989) Effects of some natural and artificial substrata on sessile marine organisms at Galeta Reef, Panama. Mar Ecol Prog Ser 52:201-208

Menge BA (1976) Organization of the New England rocky intertidal community: role of predation, competition, and environmental heterogeneity. Ecol Monogr 46:355-393

Minchinton TE, Scheibling RE (1991) The influence of larval supply and settlement on the population structure of barnacles. Ecology 72:1867-1879

Mullineaux LS, Butman CA (1991) Initial contact, exploration and attachment of barnacle (Balanus amphitrite) cyprids settling in flow. Mar Biol 110:93-103

People J (2006) Mussel beds on different types of structures

Editorial responsibility: Roger Hughes (Contributing Editor), Bangor, UK support different macroinvertebrate assemblages. Aust Ecol 31:271-281

Quinn GP, Keough MJ (2003) Experimental design and data analysis for biologists. Cambridge University Press

Roughgarden J, Pennington T, Alexander S (1994) Dynamics of the rocky intertidal zone with remarks on the generalization in ecology. Phil Trans R Soc Lond B 343:79-85

Thomas L (1997) Retrospective power analysis. Conserv Biol $11: 276-280$

Underwood AJ (1999) Experiments in ecology. Their logical design and interpretation using analysis of variance. Cambridge University Press

Underwood AJ (2006) Why overgrowth of intertidal encrusting algae does not always cause competitive exclusion? J Exp Mar Biol Ecol 330:221-233

Underwood AJ, Fairweather PG (1989) Supply-side ecology and benthic marine assemblages. Trends Ecol Evol 4:16-20

Underwood AJ, Jernakoff P (1984) The effects of tidal height, wave-exposure, seasonality and rock-pools on grazing and the distribution of intertidal macroalgae in New South Wales. J Exp Mar Biol Ecol 75:71-96

Williams GA (1994) The relationship between shade and molluscan grazing in structuring communities on a moderatelyexposed tropical rocky shore. J Exp Mar Biol Ecol 178: $79-95$

Submitted: January 19, 2006; Accepted: May 23, 2006 Proofs received from author(s): November 7, 2006 